\title{
Attempted Colonic Preservation Strategies Do Not Increase the Risk of In-Hospital Mortality in Patients Presenting with Acute Left-Sided Colonic Emergencies
}

\author{
Mathew A. Kozman ${ }^{1,2,3,4}$, Oliver M. Fisher ${ }^{4,5,6}$, Havish Srinath ${ }^{1,3}$, Stephen I. White ${ }^{1,2,3}$ \\ ${ }^{1}$ Department of General Surgery, The Tweed Hospital, Tweed Heads, Australia \\ ${ }^{2}$ Department of General Surgery, John Flynn Private Hospital, Tugun, Australia \\ ${ }^{3}$ Bond University, Robina, Australia \\ ${ }^{4}$ University of New South Wales Department of Surgery, St George Hospital, Kogarah, Australia \\ ${ }^{5}$ St Vincent's Centre for Applied Medical Research, Sydney, Australia \\ ${ }^{6}$ School of Medicine, University of Notre Dame, Sydney, Australia \\ Email: makozman@gmail.com
}

How to cite this paper: Kozman, M.A. Fisher, O.M., Srinath, H. and White, S.I. (2017) Attempted Colonic Preservation Strategies Do Not Increase the Risk of In-Hospital Mortality in Patients Presenting with Acute Left-Sided Colonic Emergencies. Open Journal of Gastroenterology, 7, 316-328.

https://doi.org/10.4236/ojgas.2017.712033

Received: November 8, 2017

Accepted: December 25, 2017

Published: December 28, 2017

Copyright (c) 2017 by authors and Scientific Research Publishing Inc. This work is licensed under the Creative Commons Attribution International License (CC BY 4.0).

http://creativecommons.org/licenses/by/4.0/

\begin{abstract}
Background. Colonic malignant obstruction and perforated diverticulitis are acute left sided colonic emergencies (ALSCE) that are typically managed with colorectal resection. Colonic preservation techniques such as laparoscopic lavage and endoscopic stenting have emerged as management options, the safety of which has been debated. We aimed to determine if these alternate colonic preservation techniques result in increased in-hospital mortality. Materials and Methods. Retrospective analysis of prospectively collected data of 210 patients with ALSCE managed from June 2001 to April 2014. Data collected included demographic, pathology type, ASA grading, operative and post-operative progress. Univariable and multivariable logistic regression was performed to determine factors contributing to treatment arm allocation and in-hospital mortality. These were performed on the whole treatment cohort, as well as per pathology subgroup. Results. 210 patients were included. Nonresectional management was attempted in 147 patients (70\%), of which 38 (26\%) required unplanned colonic resection or died in hospital. Those treated with colonic preservation were younger, had lower ASA scores and had lower Hinchey scores (in the diverticular perforation group) than those in the resection group. Female gender was the only independent predictor of increased in-hospital mortality risk. Importantly, the type of procedure performed (colonic preservation vs. resection) did not predict in-hospital mortality risk. Conclusion. Attempted colonic preservation strategies do not increase the
\end{abstract}


risk of in-hospital mortality in patients presenting with ALSCE. Given the inherent benefits of colonic preservation, these treatment strategies should be considered when managing ALSCE.

\section{Keywords}

Colorectal, Laparoscopic, Stenting, Obstruction, Perforation

\section{Introduction}

Left-sided colonic diverticular perforation and malignant obstruction are common surgical emergencies [1] [2]. Outcomes for those treated with emergency colonic resection are disappointing and associated with high rates of morbidity and mortality [3]. Although some presentations dictate the need for immediate resection, such as caecal necrosis from obstruction or uncontrolled faecal fistulae from diverticulitis, immediate resection of the colonic pathology is not mandatory and may be considered over-treatment in majority of patients. This is particularly true in patients with malignant obstruction who have incurable disease, and patients with Hinchey 1, 2 or 3 diverticular perforation in which the event often represents the first and only attack of diverticulitis. Subsequently, these patients may be more appropriately managed initially by techniques allowing colonic preservation with view to a later decision about further suitable management. These techniques include colonic stenting for malignant obstruction and laparoscopic lavage for perforated diverticulitis.

In 1994, Tejero first described that successful endoscopic colonic stenting can provide adequate decompression of colonic obstruction for the purpose of palliation or as a bridge to semi-elective single stage colorectal resection [4]. First reports of non-resectional surgical management of perforated diverticular disease by means of open debridement and drainage occurred in 1978 by Hinchey et al. [5], and were later performed laparoscopically in 1996 by O'Sullivan et al. [6]. Over the last decade, non-resectional management options have been increasingly used in these settings with varying results. As such, concern regarding the safety of these approaches has prevented their universal adoption.

Therefore, the aim of this study was to analyse prospectively collected data of a large cohort of patients to determine if alternate colonic preservation techniques for treatment of acute left sided colonic emergencies (ALSCE) results in increased in-hospital mortality.

\section{Materials and Methods}

\subsection{Treatment Setting and Patients}

A retrospective analysis of prospectively collected data from June 2001 to May 2014 of patients managed with primary colonic malignancy causing complete large bowel obstruction and perforated diverticulitis refractory to medical man- 
agement was performed. Patients with other left sided colonic pathology such as sigmoid volvulus, stercoral, colitis (ischaemic, inflammatory bowel disease, pseudomembranous), pseudo-obstruction were excluded from this study due to low patient numbers.

Patient data collected included age, gender, pathology type, American Association of Anesthesiology (ASA) grading, operative details and post-operative outcomes. This data was collected into a prospectively maintained colonic emergency database. Factors collected and analysed are seen in Table 1.

Malignant left-sided colonic obstruction was determined clinically and radiologically. These obstructions were managed either by colonic stenting, laparotomy and bowel resection, or diverting colostomy. Colonic stenting was utilised for palliation or as a bridge to later surgical resection. Patients were deemed palliative if possessing non-curable metastatic cancer, or if physically unfit for curative oncological resection. Patients who could tolerate an oral colonic preparation and was fit for surgery underwent colonic resection without consideration for stenting, and were excluded from this series. Patients with malignant colonic obstruction were grouped in the colonic preservation group if stenting was utilised for treatment. The technique of colonic stenting has previously been described by this unit [7].

Perforated diverticulitis patients who had failed medical management underwent a radiologically guided percutaneous drainage, laparoscopic peritoneal lavage or laparotomy and bowel resection. Patients who presented with minor local free gas perforation or whose collection was too small to benefit from drainage were excluded from the present analysis, as they were managed conservatively with antibiotics and bowel rest. The techniques of radiologically guided percutaneous drainage and laparoscopic peritoneal lavage have been previously described [8]. If surgical colonic resection was pursued, this was a Hartmann procedure (rectosigmoidectomy and end colostomy). The choice of management approach was determined by several factors including patient and surgeon preference, patient's fitness and degree of pathology/obstruction (including competence of ileocaecal valve and caecal viability), as well as preference and skill of endoscopist and radiologist. Surgical management decisions were at the surgical team's discretion and no fix protocols exist.

\subsection{Statistical Analysis}

Continuous variables were compared using Student's t-, Wilcoxon rank-sum, one-way analysis of variance ANOVA and/or Kruskal-Wallis tests as appropriate. Where necessary log2-transformation of data was performed to achieve normal distribution. Differences between proportions derived from categorical data were compared using Pearson's $\chi^{2}$ - or Fisher's exact test where appropriate. Data are reported as median with inter-quartile range (IQR) unless denoted otherwise. To determine factors contributing to treatment arm allocation uniand multivariable logistic regression analysis was performed. Equally, to identify 
Table 1. Comparison of patient demographic features.

\begin{tabular}{|c|c|c|c|c|}
\hline & $\begin{array}{l}\text { All patients } \\
\quad n=210\end{array}$ & $\begin{array}{l}\text { Colonic preservation group } \\
\qquad n=147\end{array}$ & $\begin{array}{l}\text { Colonic resection group } \\
\qquad n=63\end{array}$ & $P$-value ${ }^{*}$ \\
\hline Age (years) $)^{* *}$ & $73(59-81)$ & $70(56-79)$ & $75(70-83)$ & 0.004 \\
\hline Octogenarians, $n(\%)$ & $58(28)$ & $35(24)$ & $23(37)$ & 0.06 \\
\hline \multicolumn{5}{|l|}{ Gender, $n(\%)$} \\
\hline Male & $124(59)$ & $84(57)$ & $40(64)$ & \multirow[t]{2}{*}{0.39} \\
\hline Female & $86(41)$ & $63(43)$ & $23(36)$ & \\
\hline \multicolumn{5}{|l|}{ ASA Score, $n(\%)$} \\
\hline ASA I & $25(12)$ & $23(16)$ & $2(3)$ & \multirow{5}{*}{0.01} \\
\hline ASA II & $52(25)$ & $38(26)$ & $14(22)$ & \\
\hline ASA III & $103(49)$ & $69(46)$ & $34(54)$ & \\
\hline ASA IV & $28(13)$ & $17(11.6)$ & $11(18)$ & \\
\hline ASA V & $2(1)$ & - & $2(3)$ & \\
\hline \multicolumn{5}{|c|}{ Type of acute left sided colonic emergency, $n(\%)$} \\
\hline Malignant obstruction & $89(42)$ & $63(43)$ & $26(41)$ & \multirow[t]{2}{*}{0.83} \\
\hline Perforated diverticulitis & $121(58)$ & $84(57)$ & $37(59)$ & \\
\hline \multicolumn{5}{|l|}{ Site of cancer, $n(\%)$} \\
\hline Splenic flexure & $7(3)$ & $6(4)$ & $1(2)$ & \multirow{5}{*}{0.62} \\
\hline Descending & $11(5)$ & $7(5)$ & $4(6)$ & \\
\hline Sigmoid & $32(15)$ & $20(14)$ & $12(19)$ & \\
\hline Rectosigmoid & $32(15)$ & $24(16)$ & $8(13)$ & \\
\hline Missing data & $7(3)$ & $6(4)$ & $1(2)$ & \\
\hline \multicolumn{5}{|l|}{ Hinchey Classification, $n(\%)$} \\
\hline Hinchey I & $18(9)$ & $16(11)$ & $2(3)$ & \multirow{4}{*}{$<0.001$} \\
\hline Hinchey II & $29(14)$ & $27(18)$ & $2(3)$ & \\
\hline Hinchey III & $49(23)$ & $33(22)$ & $16(25)$ & \\
\hline Hinchey IV & $25(12)$ & $8(5)$ & $17(26)$ & \\
\hline \multicolumn{5}{|l|}{ Type of procedure, $n(\%)$} \\
\hline Stent & $63(30)$ & $63(43)$ & - & \multirow{4}{*}{-} \\
\hline Percutaneous drainage & $18(9)$ & $18(12)$ & - & \\
\hline Laparoscopic washout & $66(31)$ & $66(45)$ & - & \\
\hline Resection & $63(30)$ & - & $63(100)$ & \\
\hline \multicolumn{5}{|l|}{ Treatment success ${ }^{* * *}, n(\%)$} \\
\hline Yes & $173(82)$ & $118(80)$ & $55(87)$ & \multirow[t]{2}{*}{0.16} \\
\hline No & $37(18)$ & $29(20)$ & $8(13)$ & \\
\hline \multicolumn{5}{|l|}{ Reintervention, $n(\%)$} \\
\hline Yes & $19(9)$ & $17(12)$ & $2(3)$ & \multirow[t]{2}{*}{0.07} \\
\hline No & $191(91)$ & $130(88)$ & $61(96)$ & \\
\hline In hospital deaths, $n(\%)$ & $19(9)$ & $11(7)$ & $8(13)$ & 0.23 \\
\hline
\end{tabular}

Note: totals may not equal $100 \%$ due to rounding. ${ }^{*} P$-values were calculated with Pearson's chi-squared or Fisher's exact test comparing the colonic preservation vs. resection group where appropriate; ${ }^{*}$ Age presented as median with interquartile range in brackets; ${ }^{* *}$ Treatment success defined as resolution of symptoms with initial management strategy without the necessity for a re-intervention of any kind and/or in hospital death. 
factors contributing to in-hospital mortality uni- and multivariable logistic regression was performed. Both regression analyses were performed for the whole treatment cohort, as well as malignant obstruction and diverticulitis perforation subgroups separately, as each represent fairly distinct pathologies requiring different management strategies. Treatment success was defined as an initiated treatment that led to resolution of symptoms and no patient death. This was irrespective of if a re-intervention (second look, lavage etc.) was required, as this was recorded separately. Accordingly, treatment failure was defined as any attempt at treatment that resulted in in-patient death or if patients who received a colonic preservation management strategy progressed to emergency colonic resection within the same hospitalisation. All p-values $<0.05$ were regarded as statistically significant and all analyses were performed using R Statistical Packages [9].

\section{Results}

\subsection{Patient Demographics}

Between June 2001 and April 2014, 210 patients with ALSCE were treated. Of these, $89(42 \%)$ presented with malignant obstruction, and 121 (58\%) with perforated diverticulitis. Colonic preservation techniques were implemented for 147 (70\%) patients and 63 (30\%) underwent colonic resection. A comparison of patient demographic features is provided in Table 1 . Briefly, patients in the colonic resection group were older (median 75 years [IQR 70 - 83] vs 70 years [IQR 56 79 ], $\mathrm{p}=0.004)$ and had a greater proportion with high ASA scores (IV-V) $(21 \%$ vs. $11.6 \%, \mathrm{p}=0.01)$ and Hinchey grade III and IV disease (51\% vs. $27 \%, \mathrm{p}<$ 0.001). Figure 1 summarizes the outcomes of patients based on each pathology and treatment strategy.

\subsection{Outcomes of Patients Managed with a Colonic Preservation Strategy}

Of 147 patients managed with a colonic non-resection strategy, $118(80 \%)$

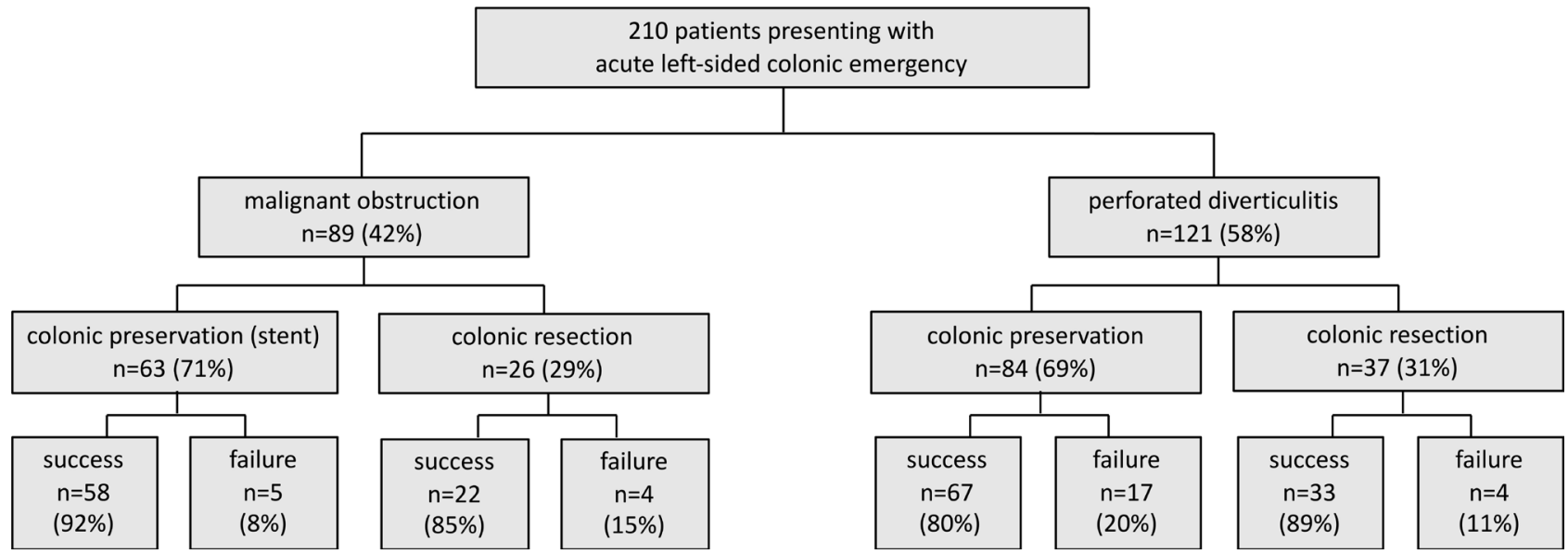

Figure 1. Summary of outcomes of patients based on each pathology and treatment strategy. 
achieved resolution of their symptoms, while 29 (20\%) underwent subsequent emergency colonic resection. Of these, 2 died and 9 others were subsequently deemed palliative and died, equating to a mortality rate of $7 \%$. As such, the overall failure rate for this management strategy was $26 \%(n=38)$.

Of 89 patients presenting with malignant colonic obstruction, 63 (71\%) had attempted colonic preservation through colonic stenting, whereas 26 (29\%) underwent emergency colonic resection in the first instance. Fifty-eight of 63 patients (92\%) who had colonic stenting had successful resolution of obstruction. The remaining 5 patients (8\%) required subsequent emergency colonic resection, all of whom survived. Seven patients (11\%) who were managed conservatively were subsequently deemed palliative and died. As such, the overall failure rate was $19 \%(\mathrm{n}=12)$.

Of 121 patients presenting with perforated diverticulitis, 84 had an attempted colonic preservation, either through percutaneous $(n=18,12 \%)$ or laparoscopic washout $(\mathrm{n}=66,45 \%)$. Fifteen $(18 \%)$ of these patients required a subsequent emergency colonic resection, two of whom died. Two further patients who were managed with colonic preservation for perforated diverticulitis subsequently died, equating to an overall mortality rate of $5 \%(n=4)$. Accordingly, the overall failure rate was $20 \%(\mathrm{n}=17)$.

There was no difference in the failure rates of attempted colonic preservation depending on the underlying presenting pathology $(p=1.00)$.

\subsection{Outcomes of Patients Undergoing Emergency Colonic Resection}

Of the 210 patients, 63 patients (30\%) underwent colonic resection in the first instance. Twenty-six (41\%) of these patients presented with malignant obstruction, whereas 37 had perforated diverticulitis (59\%).

Of the patients presenting with malignant colonic obstruction, $13(35 \%)$ had a Hartmann's procedure, 4 (11\%) a colonic resection with primary anastomosis, 2 (6\%) a subtotal colectomy with ileo-rectal anastomosis, $3(8 \%)$ a total colectomy with end-ileostomy, 3 (8\%) a diverting colostomy, and one case had missing operative information. Of these patients, 4 died equating to an overall procedure related mortality of $15 \%$.

Of the patients presenting with perforated diverticulitis, 35 (9\%) had a Hartmann's procedure, $1(3 \%)$ a colonic resection with primary anastomosis and 1 (3\%) patient underwent a total colectomy with end-ileostomy. Of these patients four subsequently died in hospital equating to a procedure specific mortality of $11 \%$. There was no difference in mortality rates depending on underlying presenting pathology $(p=0.71)$.

\subsection{Factors Contributing to Allocation to Colonic Preservation Management Strategy}

As differences existed in the distribution of certain patient demographics depending on which treatment strategy was pursued and no defined protocols were followed, a uni- and multivariable analysis was performed to determine which 
factors may predict the type of treatment adopted. The results of this analysis are presented in Table 2.

A multivariable analysis was performed across the whole cohort of patients adjusting for age, gender, ASA score and the underlying pathology of the

Table 2. Uni- and multivariable analysis for predictors of attempted colonic preservation management strategies.

\begin{tabular}{|c|c|c|c|c|c|c|}
\hline \multicolumn{7}{|c|}{ Analysis of total cohort $(n=210)$} \\
\hline \multirow[b]{2}{*}{ Variable } & \multicolumn{3}{|c|}{ Univariable analysis } & \multicolumn{3}{|c|}{ Multivariable analysis } \\
\hline & $\mathrm{OR}^{*}$ & $95 \% \mathrm{CI}^{*}$ & $P$-value & OR & $95 \% \mathrm{CI}$ & $P$-value \\
\hline Age & 0.97 & $0.95-0.99$ & 0.005 & 0.97 & $0.94-1.00$ & 0.02 \\
\hline \multicolumn{7}{|l|}{ Gender } \\
\hline Male & ref & - & & ref & - & \\
\hline Female & 1.30 & $0.71-2.42$ & 0.39 & 1.62 & $0.86-3.12$ & 0.14 \\
\hline \multicolumn{7}{|l|}{ ASA Score } \\
\hline ASA I-II & ref & - & & ref & - & \\
\hline ASA III-V & 0.48 & $0.24-0.91$ & 0.03 & 0.69 & $0.30-1.54$ & 0.38 \\
\hline \multicolumn{7}{|c|}{ Type of acute left sided colonic emergency } \\
\hline Malignant obstruction & ref & - & & ref & - & \\
\hline Perforated diverticulitis & 0.94 & $0.51-1.70$ & 0.83 & 0.70 & $0.37-1.33$ & 0.28 \\
\hline \multicolumn{7}{|c|}{ Subgroup analysis for malignant obstructions $(n=89)$} \\
\hline Age & 0.99 & $0.95-1.03$ & 0.77 & 0.95 & $0.90-1.00$ & 0.07 \\
\hline \multicolumn{7}{|l|}{ Gender } \\
\hline Male & ref & - & & ref & - & \\
\hline Female & 0.72 & $0.28-1.82$ & 0.48 & 0.99 & $0.33-3.16$ & 0.99 \\
\hline \multicolumn{7}{|l|}{ ASA Score } \\
\hline ASA I-II & ref & - & & ref & - & \\
\hline ASA III-V & 6.97 & $2.28-23.27$ & $<0.001$ & 11.68 & $3.07-54.73$ & $<0.001$ \\
\hline \multicolumn{7}{|l|}{ Site of cancer } \\
\hline Descending to sigmoid & ref & - & & ref & - & \\
\hline Rectum & 1.55 & $0.59-4.33$ & 0.39 & 1.78 & $0.60-5.73$ & 0.31 \\
\hline \multicolumn{7}{|c|}{ Subgroup analysis for diverticulitis perforations $(n=121)$} \\
\hline Age & 0.96 & $0.93-0.98$ & 0.002 & 0.99 & $0.94-1.03$ & 0.47 \\
\hline \multicolumn{7}{|l|}{ Gender } \\
\hline Male & ref & - & & ref & - & \\
\hline Female & 2.05 & $0.91-4.82$ & 0.09 & 3.81 & $1.38-11.44$ & 0.01 \\
\hline \multicolumn{7}{|l|}{ ASA Score } \\
\hline ASA I-II & ref & - & & ref & - & \\
\hline ASA III-V & 0.08 & $0.03-0.22$ & $<0.001$ & 0.11 & $0.03-0.37$ & $<0.001$ \\
\hline \multicolumn{7}{|l|}{ Hinchey Classification } \\
\hline Hinchey I-II & ref & - & & ref & - & \\
\hline Hinchey III-IV & 0.12 & $0.03-0.32$ & $<0.001$ & 0.20 & $0.05-0.63$ & 0.009 \\
\hline
\end{tabular}

${ }^{*} \mathrm{OR}=$ odds ratio; $95 \% \mathrm{CI}=95 \%$ confidence interval 
ALSCE. Only increased age was an independent predictor of the treatment type allocation (adjusted OR 0.97, 95\%CI 0.94 - 1.00; Table 2).

In an analogous fashion a subgroup analysis was performed for only patients presenting with malignant obstructions or perforated diverticulitis. For patients with underlying malignant obstruction, increased ASA score was a significant predictor of colonic preservation management strategy when adjusting for age, gender, ASA score and site of the primary tumour (adjusted OR 11.68, 95\%CI 3.07 - 54.73; $\mathrm{p}<0.001$ ). On the other hand, in the subgroup analysis of patients with perforated diverticulitis, increased ASA as well as Hinchey scores significantly reduced the likelihood of being managed with a colonic preservation strategy when adjusting for age, gender, ASA score and the Hinchey grade of disease (adjusted OR 0.11, 95\%CI $0.03-0.37$; $p<0.001$ and adjusted OR 0.20, $95 \%$ CI $0.05-0.63, \mathrm{p}=0.009$ respectively).

\subsection{Factors Contributing to In-Hospital Mortality}

In a next step, we aimed to determine factors contributing to increased risk of in-hospital mortality (Table 3). For the whole cohort of ALSCE, only female gender was an independent predictor of increased risk of in-hospital mortality (adjusted OR 3.04, 95\%CI $1.09-9.34, \mathrm{p}=0.039$ ) when adjusting for age, gender, ASA score, the type of underlying presenting pathology and whether or not colonic preservation was attempted. Importantly, the type of procedure performed (colonic preservation vs. resection) did not predict in-hospital mortality risk (OR $0.60,95 \% \mathrm{CI} 0.22-1.17, \mathrm{p}=0.33$ ). Factors contributing to in-hospital mortality in the subgroup analysis are presented in Table 3. Of note is that in the patients presenting with perforated diverticulitis, the type of colonic preservation attempt (drainage, washout etc.) was not predictive of in-hospital mortality (data not shown).

\section{Discussion}

Our study analysed prospectively collected data of a large cohort of consecutive patients treated for ALSCE. We found that alternate colonic preservation techniques do not increase the risk of in-hospital mortality. Furthermore, those treated with colonic preservation were younger, had lower ASA scores and lower Hinchey scores. Non-resection strategies failed in $26 \%$. Female gender was the only independent predictor of increased risk of in-hospital mortality.

Patients who present with ALSCE are often elderly and frail with multiple comorbidities, findings congruent with our cohort of patients. Moreover, upon emergency presentation these patients are generally unwell with dehydration, electrolyte imbalance and friable colon due to obstruction or inflammation. Emergency colorectal procedures requiring laparotomy, are less likely to involve primary anastomosis, frequently involve stoma formation, and are associated with higher morbidity and mortality than if performed electively [10]. It is well reported that patients with stomas experience significant morbidity, poorer 
Table 3. Uni- and multivariable analysis for predictors of in hospital mortality.

\begin{tabular}{|c|c|c|c|c|c|c|}
\hline \multicolumn{7}{|c|}{ Analysis of total cohort $(n=210)$} \\
\hline \multirow{2}{*}{ Variable } & \multicolumn{3}{|c|}{ Univariable analysis } & \multicolumn{3}{|c|}{ Multivariable Analysis } \\
\hline & OR & $95 \% \mathrm{CI}$ & $P$-value & OR & $95 \% \mathrm{CI}$ & $P$-value \\
\hline Age & 1.06 & $1.02-1.12$ & 0.008 & 1.04 & $0.99-1.10$ & 0.12 \\
\hline \multicolumn{7}{|l|}{ Gender } \\
\hline Male & ref & - & & ref & - & \\
\hline Female & 3.50 & $1.32-10.34$ & 0.015 & 3.04 & $1.09-9.34$ & 0.039 \\
\hline \multicolumn{7}{|l|}{ ASA Score } \\
\hline ASA I-II & ref & - & & ref & - & \\
\hline ASA III-V & 3.37 & $1.08-14.86$ & 0.06 & 1.56 & $0.40-7.91$ & 0.55 \\
\hline \multicolumn{7}{|c|}{ Type of acute left sided colonic emergency } \\
\hline Malignant obstruction & ref & - & & ref & - & \\
\hline Perforated diverticulitis & 0.50 & $0.19-1.30$ & 0.16 & 0.58 & $0.21-1.58$ & 0.29 \\
\hline \multicolumn{7}{|l|}{ Attempted colonic preservation } \\
\hline No & ref & - & & ref & - & \\
\hline Yes & 0.56 & $0.21-1.51$ & 0.23 & 0.60 & $0.22-1.71$ & 0.33 \\
\hline \multicolumn{7}{|c|}{ Subgroup analysis for malignant obstructions $(n=89)$} \\
\hline Age & 1.04 & $0.98-1.12$ & 0.24 & 1.02 & $0.94-1.12$ & 0.65 \\
\hline \multicolumn{7}{|l|}{ Gender } \\
\hline Male & ref & - & & ref & - & \\
\hline Female & 4.76 & $1.27-23.09$ & 0.03 & 3.52 & $0.73-20.46$ & 0.13 \\
\hline \multicolumn{7}{|l|}{ ASA Score } \\
\hline ASA I-II & ref & - & & ref & - & \\
\hline ASA III-V & 1.07 & $0.24-7.51$ & 0.93 & 1.40 & $0.15-17.77$ & 0.77 \\
\hline \multicolumn{7}{|l|}{ Site of cancer } \\
\hline Descending to sigmoid & ref & - & & ref & - & \\
\hline Rectum & 16.33 & $2.77-312.06$ & 0.01 & 19.67 & $3.02-401.37$ & 0.009 \\
\hline \multicolumn{7}{|l|}{ Attempted colonic preservation } \\
\hline No & ref & - & & ref & - & \\
\hline Yes & 0.69 & $0.19-2.84$ & 0.58 & 0.32 & $0.04-2.28$ & 0.25 \\
\hline \multicolumn{7}{|c|}{ Subgroup analysis for diverticulitis perforations $(n=121)$} \\
\hline Age & 1.09 & $1.02-1.19$ & 0.03 & 1.08 & $1.00-1.21$ & 0.09 \\
\hline \multicolumn{7}{|l|}{ Gender } \\
\hline Male & ref & - & & ref & - & \\
\hline Female & 2.52 & $0.59-12.77$ & 0.22 & 2.21 & $0.43-13.52$ & 0.35 \\
\hline \multicolumn{7}{|l|}{ ASA Score } \\
\hline ASA I-II & ref & - & & ref & - & \\
\hline ASA III-V & 7.65 & $1.3-1.45$ & 0.06 & 1.43 & $0.15-33.24$ & 0.77 \\
\hline \multicolumn{7}{|l|}{ Hinchey Classification } \\
\hline Hinchey I-II & ref & - & & ref & - & \\
\hline Hinchey III-IV & 4.81 & $0.82-91.41$ & 0.14 & 4.18 & $0.56-88.60$ & 0.22 \\
\hline \multicolumn{7}{|l|}{ Attempted colonic preservation } \\
\hline No & ref & - & & ref & - & \\
\hline Yes & 0.41 & $0.09-1.84$ & 0.22 & 0.80 & $0.14-4.38$ & 0.79 \\
\hline
\end{tabular}


quality of life and negative psychosocial impact [11] [12]. Thus, the concept of colonic preservation strategies is appealing due to the several inherent benefits it affords. These include shorter and less invasive procedures, less recovery time, lower morbidity (wound infection, stoma avoidance, anastomotic dehiscence), and subsequent shorter length of hospital stay. However, concerns regarding the safety and reoperation rate following these approaches have prevented widespread adoption. Our data indicate that attempts at colonic preservation are safe treatment options.

With regards to malignant colorectal obstruction, some authors suggest increased postoperative mortality in patients undergoing emergency versus elective resection [10] [13]. Furthermore, emergency operations delay administration of chemotherapy and may impair the immunological response to cancer whilst facilitating recovery. Hence, converting an emergency procedure to an elective scenario is an attractive prospect and may be facilitated by placement of a colonic stent, allowing for colonic decompression, accurate staging, assessment for synchronous cancers, optimisation of comorbidities and nutrition, and even bowel preparation [14]. However, there have been conflicting results regarding complication rates (especially perforation) [15] [16] [17], and subsequent negative oncological outcomes [18] [19]. Recent systematic reviews and meta-analyses of studies that employed self-expanding metal stents have showed promising results, with variable technical and clinical success rates but comparable mortality rates [14] [20] [21] [22] [23]. In our cohort, we found similar treatment success and mortality rates.

Recent meta-analyses have suggested that laparoscopic lavage in the management of perforated diverticulitis can help avoid emergency laparotomy, resection, stoma formation and the associated morbidity, mortality and cost [24] [25] [26]. This may allow patients to avoid colonic resection altogether, or have delayed elective colonic resection. In addition, laparoscopic lavage also allows for accurate Hinchey classification of patients' disease (especially differentiation between purulent and feculent peritonitis), and subsequent early selection of those who require resection [27]. More recent randomised trials report similar results when common end points are considered, in that the major morbidity and mortality rates were similar between the laparoscopic lavage and resection groups [27] [28] [29]. We found similar success and mortality rates between the two treatment groups.

Our audit of 210 consecutive ALSCE commenced in 2001 following our first colonic stent and laparoscopic lavage. The learning curve for non-resection techniques was influenced by varying levels of experience and enthusiasm amongst surgeons involved in emergency after-hours care. However, continued success in managing patients without resection resulted in greater adoption of these techniques. Of the 147 patients initially offered non-resection therapy, $13.6 \%$ underwent resection during the same admission, none of which died. Most of these occurred early in the audit period, when there was a lower thresh- 
old for resection if concerns arose regarding patient progress after non-resectional treatment. More recently, patients have undergone second attempts at non-resection management if the result of the first procedure was under question, and if safe to do so.

We recognise the inherent limitations of our study. Firstly, it is a retrospective cohort, which may be prone to selection bias. Secondly, no standardised treatment protocols existed and therefore allocation to a particular treatment arm may have been confounded. However, in an attempt to address this, a multivariable analysis was performed to identify factors that may have determined the allocation to a particular treatment arm. Lastly, we acknowledge that two distinct pathologies have been included in our study, which may represent a potential confounder. However, in our multivariable analysis of in-hospital mortality, the pathology type was not a predictor. Furthermore, subgroup analysis was performed for each distinct pathology group to allow for more granular consideration of our data.

\section{Conclusion}

Attempted colonic preservation strategies do not increase the risk of in-hospital mortality in patients presenting with acute left-sided colonic malignant obstruction and perforated diverticulitis. This approach affords several inherit benefits, and as such should be considered when managing patients with ALSCE. Careful patient selection and procedural experience is pivotal to the success of this approach. In addition, female gender was the only independent predictor of increased risk of in-hospital mortality in our cohort.

\section{References}

[1] McGrath, D.R., Leong, D.C., Armstrong, B.K. and Spigelman, A.D. (2004) Management of Colorectal Cancer Patients in Australia: the National Colorectal Cancer Care Survey. ANZ Journal of Surgery, 74, 55-64. https://doi.org/10.1046/j.1445-1433.2003.02891.x

[2] Stollman, N. and Raskin, J.B. (2004) Diverticular Disease of the Colon. Lancet, 363, 631-639. https://doi.org/10.1016/S0140-6736(04)15597-9

[3] Seah, D.W., Ibrahim, S. and Tay, K.H. (2005) Hartmann Procedure: Is It Still Relevant Today? ANZ Journal of Surgery, 75, 436-440. https://doi.org/10.1111/j.1445-2197.2005.03367.x

[4] Tejero, E., Mainar, A., Fernandez, L., Tobio, R. and De Gregorio, M.A. (1994) New Procedure for the Treatment of Colorectal Neoplastic Obstructions. Diseases of the Colon \& Rectum, 37, 1158-1159. https://doi.org/10.1007/BF02049822

[5] Hinchey, E.J., Schaal, P.G. and Richards, G.K. (1978) Treatment of Perforated Diverticular Disease of the Colon. Advances in Surgery, 12, 85-109.

[6] O'Sullivan, G.C., Murphy, D., O'Brien, M.G. and Ireland, A. (1996) Laparoscopic Management of Generalized Peritonitis Due to Perforated Colonic Diverticula. The American Journal of Surgery, 171, 432-434. https://doi.org/10.1016/S0002-9610(97)89625-0

[7] White, S.I., Abdool, S.I., Frenkiel, B. and Braun, W.V. (2011) Management of Ma- 
lignant Left-Sided Large Bowel Obstruction: A Comparison between Colonic Stents and Surgery. ANZ Journal of Surgery, 81, 257-260.

https://doi.org/10.1111/j.1445-2197.2010.05477.x

[8] White, S.I., Frenkiel, B. and Martin, P.J. (2010) A Ten-Year Audit of Perforated Sigmoid Diverticulitis: Highlighting the Outcomes of Laparoscopic Lavage. Diseases of the Colon \& Rectum, 53, 1537-1541. https://doi.org/10.1007/DCR.0b013e3181f2ee2a

[9] A.R.F.F.S.C. R Core Team (2013) R: A Language and Environment for Statistical Computing. Vienna.

[10] McArdle, C.S. and Hole, D.J. (2004) Emergency Presentation of Colorectal Cancer Is Associated with Poor 5-Year Survival. British Journal of Surgery, 91, 605-609. https://doi.org/10.1002/bjs.4456

[11] Karadag, A., Mentes, B.B., Uner, A., Irkorucu, O., Ayaz, S. and Ozkan, S. (2003) Impact of Stomatherapy on Quality of Life in Patients with Permanent Colostomies or Ileostomies. International Journal of Colorectal Disease, 18, 234-238.

[12] Nugent, K.P., Daniels, P., Stewart, B., Patankar, R. and Johnson, C.D. (1999) Quality of Life in Stoma Patients. Diseases of the Colon \& Rectum, 42, 1569-1574. https://doi.org/10.1007/BF02236209

[13] Morris, E.J., Taylor, E.F., Thomas, J.D., Quirke, P., Finan, P.J., Coleman, M.P., Rachet, B. and Forman, D. (2011) Thirty-Day Postoperative Mortality after Colorectal Cancer Surgery in England. Gut, 60, 806-813. https://doi.org/10.1136/gut.2010.232181

[14] Brehant, O., Fuks, D., Bartoli, E., Yzet, T., Verhaeghe, P. and Regimbeau, J.M. (2009) Elective (Planned) Colectomy in Patients with Colorectal Obstruction after Placement of a Self-Expanding Metallic Stent as a Bridge to Surgery: The Results of a Prospective Study. Colorectal Disease, 11, 178-183. https://doi.org/10.1111/j.1463-1318.2008.01578.x

[15] Small, A.J., Coelho-Prabhu, N. and Baron, T.H. (2010) Endoscopic Placement of Self-Expandable Metal Stents for Malignant Colonic Obstruction: Long-Term Outcomes and Complication Factors. Gastrointestinal Endoscopy, 71, 560-572. https://doi.org/10.1016/j.gie.2009.10.012

[16] van Hooft, J.E., Bemelman, W.A., Oldenburg, B., Marinelli, A.W., Lutke Holzik, M.F., Grubben, M.J., Sprangers, M.A., Dijkgraaf, M.G., Fockens, P. (2011) Collaborative Dutch Stent-In Study, Colonic Stenting versus Emergency Surgery for Acute Left-Sided Malignant Colonic Obstruction: A Multicentre Randomised Trial. The Lancet Oncology, 12, 344-352. https://doi.org/10.1016/S1470-2045(11)70035-3

[17] van Hooft, J.E., Fockens, P., Marinelli, A.W., Timmer, R., van Berkel, A.M., Bossuyt, P.M., Bemelman, W.A. and Dutch, G. (2008) Colorectal Stent, Early Closure of a Multicenter Randomized Clinical Trial of Endoscopic Stenting versus Surgery for Stage IV Left-Sided Colorectal Cancer. Endoscopy, 40, 184-191. https://doi.org/10.1055/s-2007-995426

[18] Kim, J.S., Hur, H., Min, B.S., Sohn, S.K., Cho, C.H. and Kim, N.K. (2009) Oncologic Outcomes of Self-Expanding Metallic Stent Insertion as a Bridge to Surgery in the Management of Left-Sided Colon Cancer Obstruction: Comparison with Nonobstructing Elective Surgery. World Journal of Surgery, 33, 1281-1286. https://doi.org/10.1007/s00268-009-0007-5

[19] Maruthachalam, K., Lash, G.E., Shenton, B.K. and Horgan, A.F. (2007) Tumour Cell Dissemination Following Endoscopic Stent Insertion. British Journal of Surgery, 94, 1151-1154. https://doi.org/10.1002/bjs.5790 
[20] Cirocchi, R., Farinella, E., Trastulli, S., Desiderio, J., Listorti, C., Boselli, C., Parisi, A., Noya, G. and Sagar, J. (2013) Safety and Efficacy of Endoscopic Colonic Stenting as a Bridge to Surgery in the Management of Intestinal Obstruction Due to Left Colon and Rectal Cancer: A Systematic Review and Meta-Analysis. Surgical Oncology, 22, 14-21. https://doi.org/10.1016/j.suronc.2012.10.003

[21] Matsuda, A., Miyashita, M., Matsumoto, S., Matsutani, T., Sakurazawa, N., Takahashi, G., Kishi, T. and Uchida, E. (2015) Comparison of Long-Term Outcomes of Colonic Stent as "Bridge to Surgery" and Emergency Surgery for Malignant Large-Bowel Obstruction: A Meta-Analysis. Annals of Surgical Oncology, 22, 497-504. https://doi.org/10.1245/s10434-014-3997-7

[22] Sagar, J. (2011) Colorectal Stents for the Management of Malignant Colonic Obstructions. Cochrane Database of Systematic Reviews, No. 11, CD007378. https://doi.org/10.1002/14651858.CD007378.pub2

[23] Watt, A.M., Faragher, I.G., Griffin, T.T., Rieger, N.A. and Maddern, G.J. (2007) Self-Expanding Metallic Stents for Relieving Malignant Colorectal Obstruction: A Systematic Review. Annals of Surgery, 246, 24-30. https://doi.org/10.1097/01.sla.0000261124.72687.72

[24] Afshar, S. and Kurer, M.A. (2012) Laparoscopic Peritoneal Lavage for Perforated Sigmoid Diverticulitis. Colorectal Disease, 14, 135-142.

https://doi.org/10.1111/j.1463-1318.2011.02606.x

[25] Rogers, A.C., Collins, D., O’Sullivan, G.C. and Winter, D.C. (2012) Laparoscopic Lavage for Perforated Diverticulitis: A Population Analysis. Diseases of the Colon \& Rectum, 55, 932-938. https://doi.org/10.1097/DCR.0b013e31826178d0

[26] Toorenvliet, B.R., Swank, H., Schoones, J.W., Hamming, J.F. and Bemelman, W.A. (2010) Laparoscopic Peritoneal Lavage for Perforated Colonic Diverticulitis: A Systematic Review. Colorectal Disease, 12, 862-867. https://doi.org/10.1111/j.1463-1318.2009.02052.x

[27] Taylor, C.J., Layani, L., Ghusn, M.A. and White, S.I. (2006) Perforated Diverticulitis Managed by Laparoscopic Lavage. ANZ Journal of Surgery, 76, 962-965. https://doi.org/10.1111/j.1445-2197.2006.03908.x

[28] Angenete, E., Thornell, A., Burcharth, J., Pommergaard, H.C., Skullman, S., Bisgaard, T., Jess, P., Lackberg, Z., Matthiessen, P., Heath, J., Rosenberg, J. and Haglind, E. (2016) Laparoscopic Lavage Is Feasible and Safe for the Treatment of Perforated Diverticulitis with Purulent Peritonitis: The First Results from the Randomized Controlled Trial DILALA. Annals of Surgery, 263, 117-122. https://doi.org/10.1097/SLA.0000000000001061

[29] Vennix, S., Musters, G.D., Mulder, I.M., Swank, H.A., Consten, E.C., Belgers, E.H., van Geloven, A.A., Gerhards, M.F., Govaert, M.J., van Grevenstein, W.M., Hoofwijk, A.G., Kruyt, P.M., Nienhuijs, S.W., Boermeester, M.A., Vermeulen, J., van Dieren, S., Lange, J.F. and Bemelman, W.A. (2015) Laparoscopic Peritoneal Lavage or Sigmoidectomy for Perforated Diverticulitis with Purulent Peritonitis: A Multicentre, Parallel-Group, Randomised, Open-Label Trial. The Lancet, 386, 1269-1277. https://doi.org/10.1016/S0140-6736(15)61168-0 